\title{
Nitroxide-enhanced magnetic resonance imaging of kidney dysfunction in vivo based on redox-imbalance and oxidative stress
}

\author{
Dessislava Lazarova $^{1}$, Sayaka Shibata ${ }^{2}$, Itsuko Ishii ${ }^{3}$, Genoveva Zlateva ${ }^{1}$, Zhivko Zhelev ${ }^{4,5}$, \\ Ichio Aoki ${ }^{2,6}$, Tatsuya Higashi ${ }^{6}$ and Rumiana Bakalova ${ }^{1,2,6}$ \\ ${ }^{1}$ Medical Faculty, Sofia University "St. Kliment Ohridski”, Sofia, Bulgaria \\ ${ }^{2}$ Quantum-state Controlled MRI Group, National Institutes for Radiological Science and Technology (QST), Chiba, \\ Japan \\ ${ }^{3}$ Chiba University Hospital, Chiba University, Chiba, Japan \\ ${ }^{4}$ Medical Faculty, Trakia University, Stara Zagora, Bulgaria \\ ${ }^{5}$ Institute of Biophysics and Biomedical Engineering, Bulgarian Academy of Sciences, Sofia, Bulgaria \\ ${ }^{6}$ Department of Molecular Imaging and Theranostics, National Institute of Radiological Sciences (NIRS), Chiba, Japan
}

\begin{abstract}
This study reports a non-invasive magnetic resonance imaging (MRI) of kidney dysfunction in mice, based on the induction of redox-imbalance and oxidative stress in the renal tissues, using mitoTEMPO as redox-sensitive contrast probe. Kidney dysfunction was triggered by hypercholesterolemia. The mice were divided in three groups: (i) on normal diet (ND); (ii) on cholesterol diet (CD); (iii) on cholesterol plus cholestyramine diet (CC). After 15 weeks feeding, the mice were subjected to the following analyses: plasma cholesterol levels; serum test for renal functionality; nitroxide-enhanced MRI of tissue redox-status in vivo; histochemical staining of tissue section to visualize renal damage; evaluation of total antioxidant capacity and oxidative stress on isolated tissue specimens. MRI signal of mito-TEMPO in the kidney was characterized by: high intensity and long life-time in CD mice, indicating a high oxidative capacity of renal tissues; poor intensity and short life-time in ND mice, indicating a high reducing capacity; moderate intensity and relatively short life-time in CC mice, indicating a protective effect of lipid-lowering drug. The data were confirmed on isolated tissue specimens, using conventional tests. They suggest that hypercholesterolemia induces redox-imbalance in kidney and this process could be visualized using MRI and mito-TEMPO as a redox-sensitive contrast.
\end{abstract}

Key words: Hypercholesterolemia - Kidney dysfunction - Redox-imbalance - Oxidative stress - Magnetic resonance imaging - Cyclic nitroxides

\section{Introduction}

The most commonly used techniques to visualize kidney function are contrast-enhanced magnetic resonance imaging (MRI), computed tomography and ultrasonography (El-Baz

Electronic supplementary material. The online version of this article (doi: 10.4149/gpb_2019001) contains supplementary material, which is available to authorized users.

Correspondence to: Rumiana Bakalova, Group of Quantum-state Controlled MRI, National Institute of Radiological Sciences (QSTNIRS), 4-9-1 Anagawa, Inage-ku, Chiba 263-8555, Japan E-mail: bakalova.rumiana@qst.go.jp. et al. 2006; Prowle et al. 2010; Dong et al. 2014). However, the use of contrast substances increases the risk of intoxication in patients with impaired renal filtration due to their retention in the organism. The efforts of clinicians and researchers are focused in two directions: (i) development of non-contrast methods for visualization and assessment of renal dysfunction; and (ii) development of non-toxic or very low toxic contrast substances for functional urography (Bagshaw and Culleton 2006; Bashir et al. 2013; Milman et al. 2014).

Renal dysfunction is mainly caused by inflammatory and/or atherogenic factors and is accompanied by a redoxdysbalance, resulting in decreased antioxidant (reducing) capacity and oxidative stress (Kon et al. 2011; Betjes 2013). 
The prolonged effect of these factors leads to irreversible structural damage of kidneys and development of renal failure - a severe pathology, in which the life of patient is maintained through hemodialysis to find a suitable donor for renal transplantation. In this context, early diagnosis of renal dysfunction and prevention of renal failure has a significant social impact.

The redox-status of cells, tissues and body fluids is very sensitive to inflammatory and atherogenic factors. This is one of the main parameters, monitored in clinical trials of chronic kidney disease and renal transplantation (Vostalova et al. 2012; Tucker et al. 2013; Ilori et al. 2015). We assume that redox-status can also be used as a biomarker for early renal injury.

The tissue redox-status is determined by the balance between the endogenous redox-active compounds: (i) oxidizers (e.g., reactive oxygen and nitrogen species (ROS/ RNS)); and (ii) reducers (e.g., antioxidant systems, thiolcontaining proteins, endogenous redox-pairs) (Georgieva et al. 2017). Significant progress has been made in the selective localized detection of many redox-active compounds (Kalyanaraman et al. 2012; Dikalov and Hrrison 2014; Bacic et al. 2016; Maulucci et al. 2016). This progress is due to the development of new synthetic or genetically encoded redox-sensitive contrast substances and improvement of visualization techniques: fluorescence, chemiluminescence, magnetic resonance, nuclear, ultrasonic.

There are many contrast substances that form detectable products reflecting the localization and level of a particular redox-active compound or group of compounds in the investigated biological object. The detection of most of these (e.g., fluorescent contrast agents) is feasible with high sensitivity and resolution in vitro, but is very difficult to implement in vivo. In another group of contrasts (e.g., nuclear and ultrasound), it is possible to achieve in vivo detection with high sensitivity, but the resolution is low. Generally, nuclear contrast substances provide indirect information about tissue redox-status, based on its relationship to various biochemical and physiological processes, for example: glucose or oxygen consumption, hypoxia, cell retention depending on the cytoplasmic redox-potential, and others. These contrasts are also radioactive, which adds additional risk to the patient. It should be noted that the above-mentioned methodologies allow assessment of the redox-status of the biological object based on the information, obtained for one or several redoxactive compounds. Thus, the discussions and conclusions in the various studies are often contradictory.

At present, the efforts are focused on mapping the redoxstatus of tissues and organs in intact organisms. The perfect methodology should provide a direct and non-invasive detection of the redox-status of the target organ in vivo. In this contexts, the perfect redox-sensitive contrast substances should meet the following conditions:
- to penetrate into the cells and through the blood-brain barrier (BBB), if possible;

- to provide information about the equilibrium between the intracellular oxidizers and reducers, respectively for the total redox-status of cells and tissues, not only for the status of a certain redox-active compound (e.g., its oxidized or reducing form);

- to be non-toxic or low-toxic in vivo;

- to have a rapid excretion through the organism;

- to have a high contrast and to allow imaging with high resolution.

Some of the most attractive redox-sensitive contrast substances are cyclic nitroxide radicals, which can be registered and analyzed in vitro and in vivo by various magnetic resonance techniques, such as electron-paramagnetic resonance imaging (EPRI), MRI and Overhauser-enhanced MRI (OMRI) (Soule et al. 2007a, 2007b; Likhtenshtein et al. 2008; Dikalov and Harrison 2014; Bacic et al. 2016). The nitroxide probes allow an assessment of the total (overall) redox-status of cells, tissues and body fluids.

The paramagnetic nitroxide radical is involved in electron-transfer reactions with oxidizers and reducers, leading to the formation of diamagnetic intermediate products (hydroxylamine and oxoammonium) (Figure 1S - Supplementary Material). The rate constants of these reactions determine the dynamics of nitroxide-enhanced MRI/EPRI signal in living biological objects.

The studies have shown that nitroxides should exist mainly in two forms in vivo - radical and hydroxylamine (Soule et al. 2007a, 2007b). Various endogenous reducers and oxidizers could be involved (directly or indirectly via oxoammonium) in the formation of diamagnetic hydroxylamine, but only the interaction of hydroxylamine with superoxide can restore the radical form of nitroxide and its contrast properties at physiological pH (7.4) (Fuchs et al. 1997; Zhang et al. 1999; Samuni et al. 2002; Bobko et al. 2007; BatinicHaberle et al. 2010; Zhelev et al. 2012; Bakalova et al. 2013; Bacic et al. 2016; Maulucci et al. 2016). Thus, the intensity of nitroxide-enhanced MRI/EPRI signal in a particular organ indicates the tissue redox-status and can serve as a marker for non-invasive assessment of oxidative stress in vivo.

The data from nitroxide-enhanced MRI/EPRI in vivo should be considered and interpreted very carefully, bearing in mind that the kinetics of the signal in the target tissue or organ depends on a number of factors: (i) life-time of nitroxide in the bloodstream; (ii) penetration through cell membranes and localization in target cells and tissues; (iii) rate of its excretion from the organism; (iv) selection of appropriate region-of-interest (ROI); (v) use of healthy individuals as controls. Ignoring even one of these factors leads to contradictions and misinterpretations.

Recently, we demonstrated that the relationship between the physicochemical properties of nitroxides and their rate of 
penetration and distribution in cells and tissues is crucial for the proper interpretation of the data from nitroxide-enhanced MRI studies in vivo (Zhelev et al. 2009a, 2009b, 2013). The rate of metabolism and excretion of nitroxide radical from the organism compete with its penetration in the target tissue and its resistance to reduction. The dynamics of nitroxideenhanced MRI signal in vivo follows all these processes.

Many in vitro MRI/EPRI studies have also shown that the nitroxide should penetrate easily and quickly into the cells and interact with intracellular reducers and oxidizers, to serve as a sensor of cellular redox-status (Swartz et al. 1986; Chen et al. 1989; Suzuki-Nishimura and Swartz 1994, 1998; Samuni et al. 2004). Nevertheless, most of the in vivo MRI/ EPRI studies of tissue redox-status have been conducted with pyrrolidine-type nitroxides, carboxy-PROXYL (CPx) and carbamoyl-PROXYL (CMPx) (Kuppusamy et al. 1998, 2002; Sano et al. 1998; Yamada et al. 2002; Matsumoto et al. 2003, 2006; Mikuni et al. 2004; Sonta et al. 2004, 2005; Hirayama et al. 2005; Tsubouchi et al. 2005; Hyodo et al. 2006a, 2006b), due to their higher resistance to reduction in biological specimens compared to the piperidine-type nitroxides. CPx and CMPx are hydrophilic and non-penetrating or poorly penetrating in the cells and tissues, as well as they are excreted very rapidly through the kidneys in normal conditions (Hyodo et al. 2006b).

In this study, we used the cell-penetrating and mitochondria-penetrating nitroxide radical, mito-TEMPO, as a contrast probe for non-invasive imaging of kidney dysfunction in mice, based on the induction of redox-dysbalance and oxidative stress in the renal tissues. The renal dysfunction was triggered by hypercholesterolemia and subsequent development of glomerulosclerosis. Healthy mice were used as controls. The dynamics of the MRI signal of mito-TEMPO in the kidneys was compared to that of CMPx.

\section{Materials and Methods}

\section{Animals}

The care, maintenance, and experiments with animals were in accordance to the "Principles of Laboratory Animal Care" (NIH publication number 85-23, revised 1985) and the Guidelines of the Animal Investigation Committee of the National Institute of Radiological Sciences (QST-NIRS, Chiba, Japan).

Male C57Bl/6 mice were purchased from Japan SLC Inc. (Shizuoka, Japan). Mice were subjected to a normal diet (ND group) (MF; Oriental Yeast Co., Tokyo, Japan) or a cholesterol diet (CD group) (ATT6492210; 1.25\% [wt/wt] cholesterol, Oriental Yeast Co.), starting at 5-weeks of age. CD mice were divided in two groups: (i) on a CD diet; (ii) on a cholesterol diet, containing 3\% cholestyramine (CC group).
Throughout the experiments, the mice were kept in stainless steel cages with food and water available ad libitum and maintained on a 12-hours light-dark cycle.

\section{MRI measurements}

The MRI measurements were performed on 7.0 Tesla horizontal magnet (Kobelco and Jastec, Kobe, Japan) interfaced to a Bruker Avance-I console (Bruker BioSpin, Rheinstetten, Germany) and controlled with ParaVision 4.0.1 (Bruker BioSpin).

Mice were anesthetized by isoflurane (2.0\%, Abbott Japan, Tokyo, Japan) and placed in a body holder (Rapid Biomedical, Rimpar, Germany), stomach side down and fixed head. Polyethylene catheter (PE-10, Becton-Dickinson, NJ, USA) was placed in the tail vein for probe administration. The mouse was then placed in the ${ }^{1} \mathrm{H}$-volume coil for mouse body with $35 \mathrm{~mm}$ in diameter $(\mathrm{Tx} / \mathrm{Rx})$. Rectal temperature of the mouse was maintained at $36.5 \pm 0.5^{\circ} \mathrm{C}$ using a circulating hot water pad and monitored using an optical temperature probe (FOT-L and FTI-10, FISO Technologies Inc., Germany). A respiration sensor (TDS160A, BIOPAC Systems Inc., CA, USA) was placed on the chest of the mouse for monitoring.

Initially, for the selection of region-of-interest (ROI), high resolution $\mathrm{T}_{2}$-weighted $\left(\mathrm{T}_{2} \mathrm{~W}\right)$ spin-echo MRI was used. After proper positioning of the slices in the area of kidney, five control images of the mouse body were acquired before nitroxide administration, with the following parameters: $\mathrm{T}_{1} \mathrm{~W}$ incoherent gradient-echo sequence (fast low-angle shot); repetition time $=75 \mathrm{~ms}$; echo time $=3.2 \mathrm{~ms}$; flip angle $=45$ degrees; number of averages $=4$; scan time $=19.2$ seconds; matrix $=64 \times 64$; slice thickness $=1 \mathrm{~mm}$; number of slices $=5$. We selected the coronal slice orientations with a 300 $\times 300 \times 1000 \mu \mathrm{m}^{3}$ nominal voxel resolution. Ninety-six seconds after starting the MRI scan (5 images acquired as pre-administration data), $100 \mathrm{ml}$ of nitroxide probe (mitoTEMPO; Santa Cruz Biotechnology, Dallas, TX, USA) per $25 \mathrm{~g}$ mouse were injected via the tail vein during scanning. $\mathrm{T}_{1}$-weighted images were acquired continuously within $\sim 15$ min. Mito-TEMPO was dissolved in phosphate-buffered saline (10 mM PBS, pH 7.4) to $100 \mathrm{mM}$ stock solution.

Three ROIs were selected: (i) the whole kidney; (ii) renal cortex; (iii) renal medulla.

The MRI data were analyzed using the ImageJ software (National Institute of Health, Bethesda, MD, USA). The intensity of the nitroxide-enhanced MRI signal in the kidney area (ROI) was normalized to the average intensity of the MRI signal in the same area before injection of mito-TEMPO (first five scans).

\section{Analysis of plasma cholesterol levels}

Blood samples were taken from the tail vein in a heparinized microhematocrit tubes. The samples were centrifuged at 
$12,000 \times g$ for $5 \mathrm{~min}$ at room temperature, to obtain plasma. Plasma was stored at $-80^{\circ} \mathrm{C}$ until cholesterol analysis. The total cholesterol level was determined by a modification of the cholesterol oxidase method with the use of kit reagents (Wako Pure Chemical Industries, Osaka, Japan). The highdensity lipoprotein (HDL) cholesterol levels were measured by the cholesterol oxidase assay of the supernatant from the precipitate of non-HDL lipoproteins with phosphotungstic acid and magnesium chloride using the kit reagents (Wako Pure Chemical Industries). The non-HDL cholesterol levels were calculated as HDL cholesterol levels subtracted from total cholesterol levels.

\section{Total antioxidant capacity (TAC) assay}

At the end of the study, the mice were sacrificed. The kidneys were isolated, washed several times with cold phosphatebuffered saline (PBS), and homogenized in $10 \mathrm{mM}$ PBS ( $\mathrm{pH} 7.4)$ on ice $(1: 20, \mathrm{w}: \mathrm{v})$. The TAC assay was performed using an OxiSelect ${ }^{\mathrm{TM}}$ Total Antioxidant Capacity (TAC) Assay kit (Cell Biolabs, Inc., US). The method is based on the reduction of $\mathrm{Cu}^{2+}$ to $\mathrm{Cu}^{+}$by antioxidants and other reducing equivalents in the biological sample. $\mathrm{Cu}^{+}$interacts with a chromophore to obtain a color product with an absorption maximum at $490 \mathrm{~nm}$. The value of the absorption is proportional to the total antioxidant, respectively reduction capacity of the biological object.

Briefly, tissue lysates were prepared as it was described in the manufacturer's instruction. All tissue lysates were adjusted to the same protein concentration. Aliquots of the cell lysates were placed in a 96-well plate. Each cell lysate was incubated with cupper ion reagent and chromophore as it was described in the instruction. The absorption of the product at $490 \mathrm{~nm}$ was detected by a microplate reader (Tecan Infinite F200 PRO, Austria). Three independent experiments were performed for each sample, with two parallel sample measurements for each experiment.

The antioxidant capacity of the samples was determined by a calibration curve using uric acid as a standard. The results are presented as TAC, which is equivalent to "Total Reduction Capacity" in "mM Uric Acid Equivalents". One $\mathrm{mM}$ of uric acid corresponds to $2189 \mu \mathrm{M}$ of $\mathrm{Cu}^{2+}$-reducing equivalents.

\section{ROS assay}

The analysis was performed using an OxiSelect ${ }^{\mathrm{TM}}$ In Vitro ROS/RNS Assay kit (Cell Biolabs, Inc., US). The method is based on the application of fluorogenic probe - DCFHDiOxyQ (non-fluorescent). The probe interacts with ROS/ RNS, resulting in a fluorescent product - 2,7-dichloro-dihydro-fluorescein (DCF). The fluorescence intensity of DCF is proportional to the level of ROS/RNS in the biological object.
Briefly, tissue lysates were prepared as it was described above and adjusted to the same protein concentration. Aliquots of the lysates were placed in a 96-well plate. Each lysate was incubated with DCFH and treated as it was described in the manufacturer's instruction. The fluorescence of the product was detected by a microplate reader (Tecan Infinite F200 PRO, Austria) at $\lambda_{\text {ex }}=480 \mathrm{~nm}$ and $\lambda_{\text {em }}=530 \mathrm{~nm}$. Three independent experiments were performed for each sample, with two parallel sample measurements for each experiment. The level of ROS in each sample was determined by a calibration curve using DCF solution as a standard.

\section{Histochemical staining}

Isolated kidney was fixed with $4 \%$ formaldehyde in PBS overnight. The tissue was embedded in paraffin. Tissue sections were prepared and stained with hematoxylin and eosin. The analysis of stained tissue sections was performed with a microscope (Olympus FV1000, Olympus, Japan).

\section{Statistical analysis}

The results are expressed as means \pm standard error (SE) or means \pm standard deviation (SD). Comparisons between the groups were performed using Student's $t$-test. A value of $p<0.05$ was considered significant.

\section{Results and Discussion}

The mice were divided in three groups: (i) on normal diet (control) (ND); (ii) on cholesterol diet (CD); (iii) on cholesterol plus cholestyramine diet (CC). Mice were subjected to the respective diet, starting at 5-weeks of age. It was shown that cholesterol induces hypercholesterolemia (Tomizawa et al. 2011a) and cholestyramine decreases plasma cholesterol and prevents hypercholesterolemia (Hermankova et al. 2018).

Cholestyramine is an ion-exchanged polymer and bile acid sequestrant (Figure 1). Bile acids are synthesized in the liver from cholesterol and secreted to the intestine through the gallbladder. Cholestyramine binds bile acids in gastrointestinal tract, prevents their re-absorption and increases their excretion from the organism. The low level of bile acids in the portal vein and liver induces a synthesis of bile acids " $d e$ novo", which is accompanied by consumption of cholesterol and its removal from the plasma. Thus, plasma cholesterol decreases (Figure 1).

After 15-weeks of feeding, the mice were subjected to the following analyses: (i) plasma cholesterol levels; (ii) serum test, representative for renal functionality; (iii) evaluation of redox-status of the kidneys in vivo, using nitroxide-enhanced MRI and mito-TEMPO as a redox-sensor; (iv) isolation of kidneys and histochemical staining to visualize renal dam- 


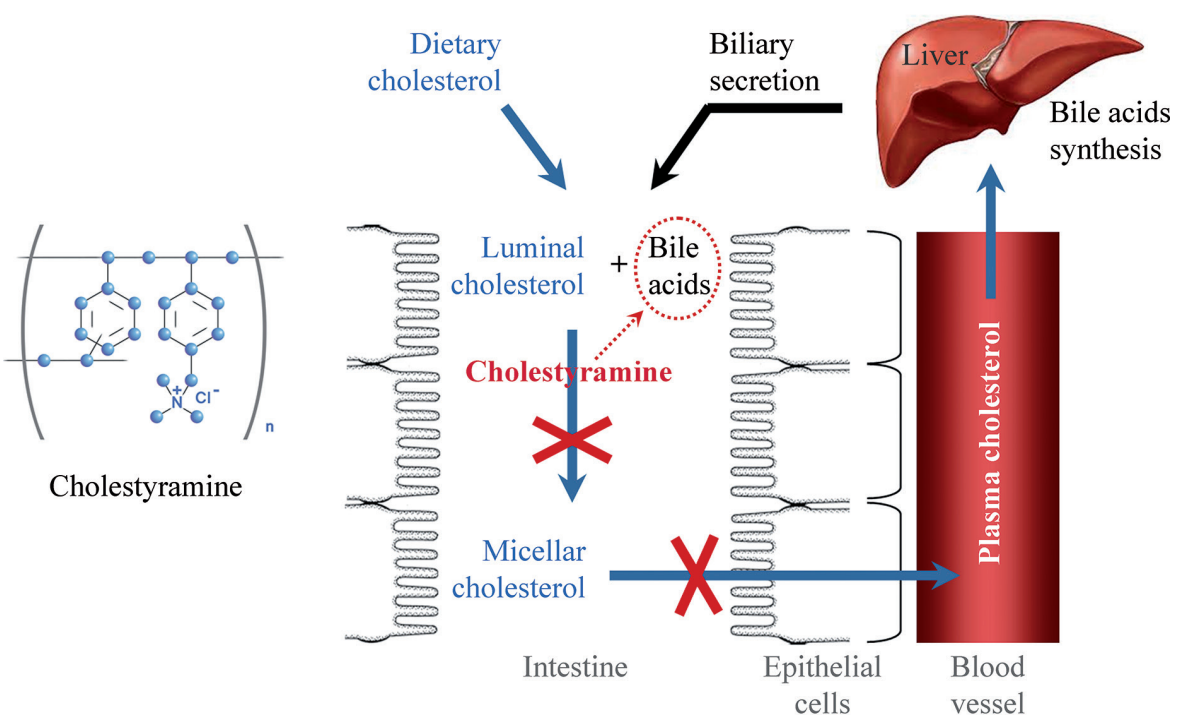

Figure 1. Structural formula and mechanism of lowering plasma cholesterol by bile acid sequestrant cholestyramine.

age; (v) preparation of tissue homogenates and evaluation of total antioxidant capacity and level of ROS using conventional biochemical tests in vitro.

The CD mice were characterized by significantly elevated levels of total plasma cholesterol and non-HDL cholesterol, and decreased levels of HDL cholesterol, compared to the
ND mice (Table 1). These data prove the development of hypercholesterolemia in CD mice. CC mice were characterized by slightly elevated total plasma cholesterol, control level of non-HDL cholesterol and slightly increased HDL cholesterol, compared to the ND mice (Table 1). These data prove the lipid-lowering effect of cholestyramine.

Table 1. Plasma cholesterol levels in mice on normal diet and high cholesterol diet with or without cholestyramine

\begin{tabular}{lrcr}
\hline \multirow{2}{*}{ Parameter } & \multicolumn{3}{c}{ Group } \\
\cline { 2 - 4 } & ND & CD & CC \\
\hline Total cholesterol (mg/dl) & $147 \pm 9$ & $535 \pm 60^{* * *}$ & $187 \pm 10^{*, \# \# \#}$ \\
Non-HDL cholesterol (mg/dl) & $16 \pm 8$ & $419 \pm 63^{* * *}$ & $15 \pm 8^{\# \# \#}$ \\
HDL cholesterol (mg/dl) & $131 \pm 9$ & $116 \pm 11$ & $172 \pm 14^{*, \# \#}$ \\
\hline
\end{tabular}

All parameters were measured on the $15^{\text {th }}$ week after feeding with high cholesterol diet with or without drug. The results are means \pm SE. ${ }^{* * *} p<0.001,{ }^{*} p<0.05 v s$. ND group; ${ }^{\# \#} p<0.001,{ }^{\# \#} p<0.01$ vs. CD group. All other variables were statistically insignificant. Each group consists of 5 mice: ND, normal diet (control); CD, cholesterol diet; CC, cholesterol plus cholestyramine diet; HDL, high-density lipoprotein.

Table 2. Biochemical test of serum for renal functionality

\begin{tabular}{lccc}
\hline \multirow{2}{*}{ Parameter } & \multicolumn{3}{c}{ Group } \\
\cline { 2 - 4 } & \multicolumn{1}{c}{ ND } & CD & CC \\
\hline Total protein $(\mathrm{g} / \mathrm{dl})$ & $5.23 \pm 0.28$ & $4.75 \pm 0.15$ & $4.98 \pm 0.25$ \\
Albumin $(\mathrm{g} / \mathrm{dl})$ & $3.04 \pm 0.21$ & $2.21 \pm 0.13^{* *}$ & $3.07 \pm 0.22^{\#}$ \\
BUN (mg/dl) & $24.15 \pm 1.76$ & $31.03 \pm 4.48^{*}$ & $23.17 \pm 2.24$ \\
CRE (mg/dl) & $0.18 \pm 0.03$ & $0.29 \pm 0.02^{* *}$ & $0.20 \pm 0.04^{\star}$ \\
UA (mg/dl) & $1.57 \pm 0.14$ & $2.55 \pm 0.21^{*}$ & $1.88 \pm 0.25^{\star}$ \\
\hline
\end{tabular}

All parameters were measured on the $15^{\text {th }}$ week after feeding with high cholesterol diet with or without drug. The results are means \pm SE. ${ }^{* *} p<0.01,{ }^{*} p<0.05 v s$. ND group; ${ }^{\#} p<0.05 v s$. CD group. Each group consists of 5 mice. ND, normal diet (control); CD, cholesterol diet; CC, cholesterol plus cholestyramine diet; BUN, blood urea nitrogen; CRE, creatine; UA, uric acid. Other parameters (such as Na, $\mathrm{K}, \mathrm{Cl}, \mathrm{Ca}$, inorganic phosphorus) do not change significantly and are not shown in the table. 

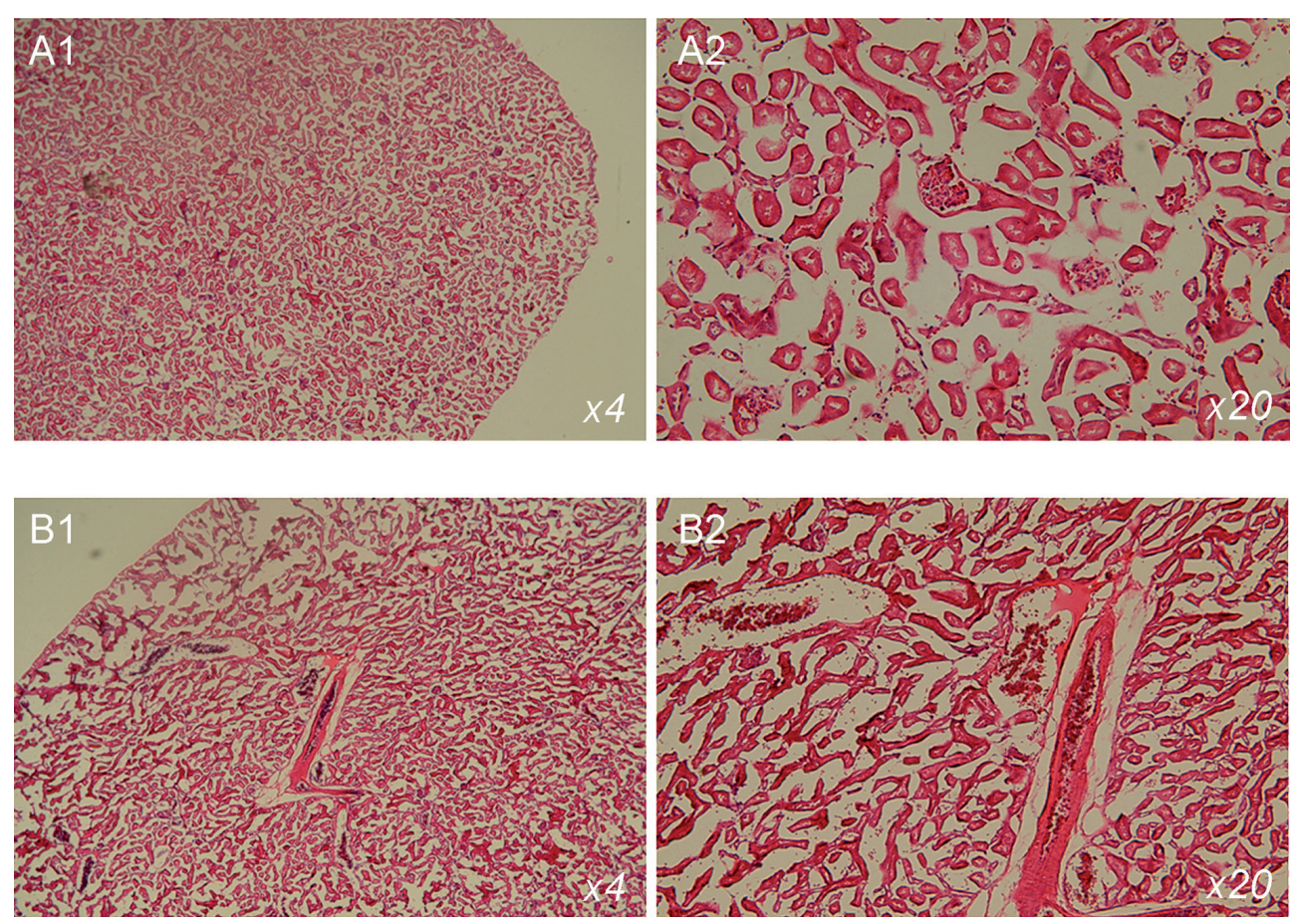

Figure 2. Hematoxylin and eosin staining of tissue sections of kidneys, isolated from mice on normal diet (ND group, A) and cholesterol diet (CD group, B). The mice were 20 weeks of age. The images indicate glomerular and tubular damage. Magnification $\times 4(\mathrm{~A} 1$, B1), $\times 20(\mathrm{~A} 2, \mathrm{~B} 2)$.

The hypercholesterolemia compromised the renal function of CD mice: blood urea nitrogen, creatine and uric acid increased significantly, compared to ND group (Table 2). In $\mathrm{CC}$ mice, all these parameters were almost equal to the reference values, measured in ND group. Histochemical analysis, performed at the end of the study, showed glomerular and tubular lesions (Figure 2). Similar results, showing the development of renal dysfunction in experimental models of hypercholesterolemia, have been also reported by other authors (Bentley et al. 2002; Qiao et al. 2009; Fang et al. 2016).

Representative nitroxide-enhanced magnetic resonance images of kidneys are shown in Figure 3. The nitroxideenhanced signal was extracted from each image after injection of mito-TEMPO and normalized to the average baseline signal, obtained before the injection. Thus, it is possible to assess the redox-status of the nitroxide probe (oxidized/ reduced), respectively to assess the redox-capacity of the tissues in vivo. In ND mice, a weak MRI signal was detected in the kidney immediately after injection of mito-TEMPO, but it disappears completely after 3 minutes (Figure 3A). This indicates a conversion of nitroxide radical to its diamagnetic form (hydroxylamine), which can be explained by the high reducing capacity of normal (healthy) renal tissues (Figure 3A). In CD mice, a strong MRI signal was detected in the kidney immediately after injection of mito-TEMPO (Figure 3C). The intensity decreases within $15 \mathrm{~min}$, but is still above the baseline. This indicates the presence of nitroxide in paramagnetic form, which can be explained by the high oxidative capacity of the renal tissues. In CC mice, the nitroxide-enhancement is very well expressed immediately after injection of mito-TEMPO, but the signal disappears completely after $10 \mathrm{~min}$ (Figure 3B). Obviously, the renal tissues of cholestyramine-treated mice are characterized by a lower oxidative and higher reducing capacity than that of untreated CD mice.

The kinetic curves of nitroxide-enhanced MRI signal support this assumption. In the whole kidney area (ROI-1) of CD mice, the signal was long-lived and had a significantly higher intensity than that of ND mice (Figure 4A). The differences were statistically significant even in the "washout period" $(p<0.05)$. No statistically significant difference was found between the integrated MRI signals (area under the curve) in ROI-1 of CC mice and ND mice. However, there were differences in the kinetics of nitroxide-enhanced MRI signal in the renal medulla and renal cortex. In the renal medulla (ROI-2), the kinetic curves followed the same dynamics as in the whole kidney area (Figure 4B). No statistically significant difference was found between the integrated MRI signals in ROI- 2 of CC mice and ND mice. In the renal cortex (ROI-3), the signal increased in the following order: ND group $<$ CC group $<\mathrm{CD}$ group and the differences between all groups were statistically significant even in the "washout period" (Figure 4C). These data suggest that cholestyramine completely eliminates the effect of cholesterol on the redox-status of renal medulla, but not on the redox-status of renal cortex. The high signal in the renal cortex indicates high oxidative 

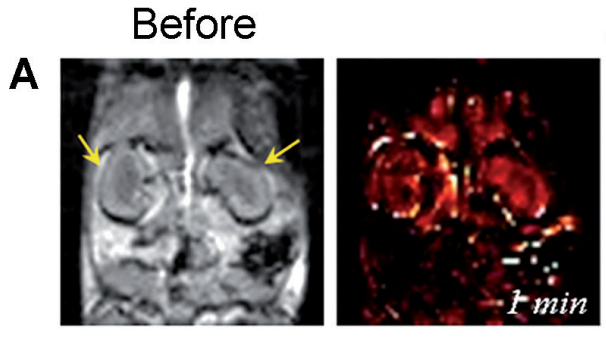

After injection of mito-TEMPO
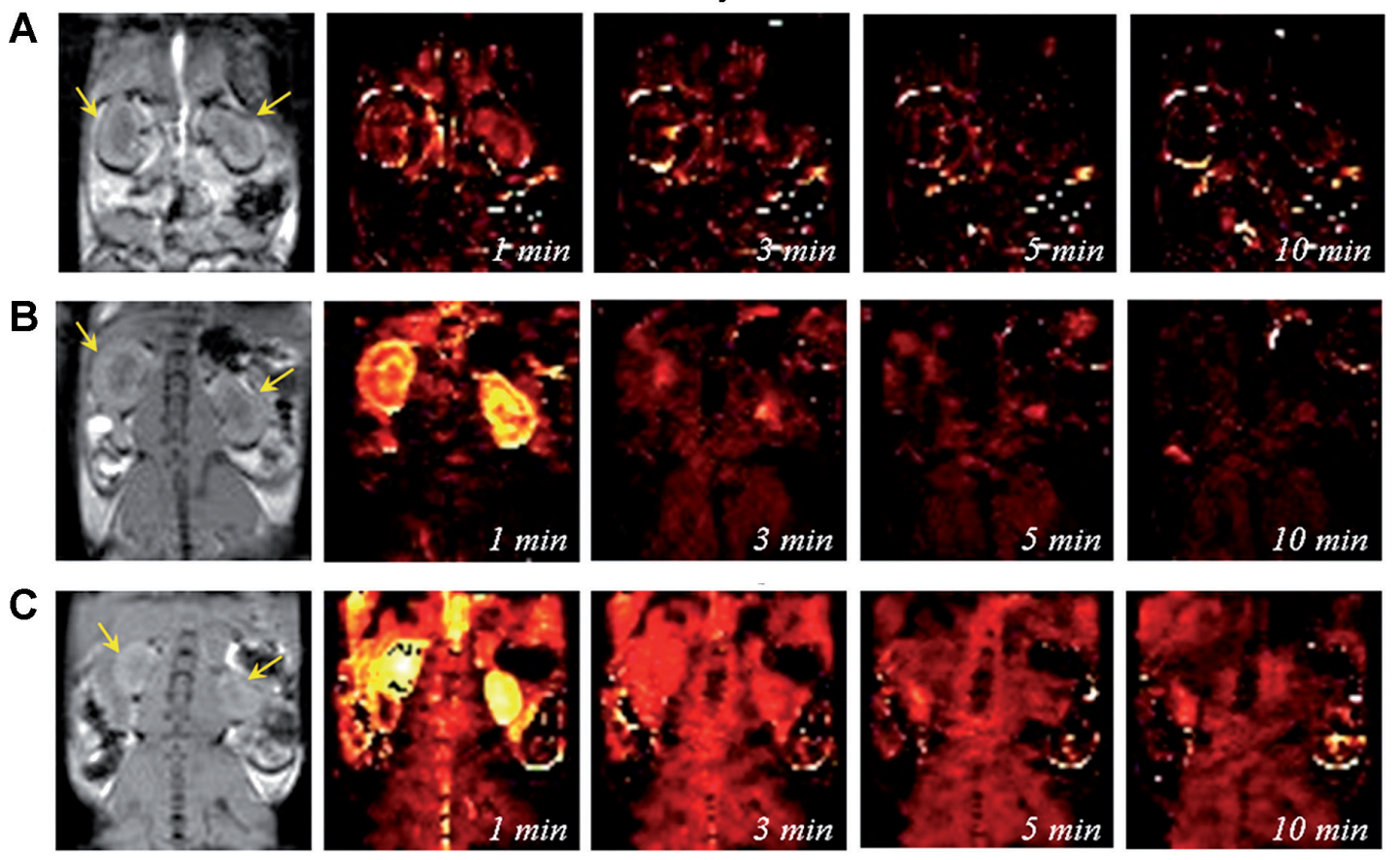

Figure 3. Representative nitroxide-enhanced magnetic resonance images of kidneys in mice on normal diet (A), cholesterol plus cholestyramine diet (B) and cholesterol diet (C). Black \& white image: $\mathrm{T}_{1}$-weighted MR images of kidneys before injection of mito-TEMPO. Color images: Extracted MRI signal intensity after injection of mito-TEMPO, normalized to the averaged baseline level (before injection of mito-TEMPO). The yellow arrows indicate the kidneys. (See online version for color figure.)

capacity and risk of injury. The observed glomerulosclerosis confirms this assumption (Figure 2).

Many experimental and clinical studies have shown that hypercholesterolemia is a risk factor for development of chronic kidney disease accompanied by structural and functional changes in this organ (Rodriguez-Porcel et al. 2001; Cheng et al. 2003; Domronkitchaiporn et al. 2005; Vogl et al. 2007; Nagata et al. 2010; Kondo et al. 2013). High level of cholesterol in the bloodstream and tissues causes inflammation and induces oxidative stress, which leads to renal fibrosis, cell apoptosis and lesions, respectively to severely impaired and reduced filtration (renal dysfunction) (Eddy 1998; Kamanna et al. 1998; Montilla et al. 2006; Hirayama et al. 2008; Okamura et al. 2009; Fang et al. 2016). Hypercholesterolemia leads to a significant decrease of reduced glutathione and ascorbate in renal lesions, indicating a redox-imbalance (Deepa and Varalakshmi 2003; Cachofeiro et al. 2008; Qiao et al. 2009). Ascorbate is the main endogenous reducer of nitroxide radical and "quencher" of its MRI contrast (Mehlhorn 1991; Bobko et al. 2007). Ascorbate and glutathione are responsible for the rapid decay of nitroxide-enhanced MRI signal in normal (healthy) kidneys. On the other hand, hypercholesterolemia-induced oxidative stress is accompanied by up-regulation of NADPH-dependent oxidase complex
(NOX) and mitochondrial dysfunction in kidneys (Gamboa et al. 2016; Wan et al. 2016), which results in overproduction of superoxide. Superoxide is the main oxidizer that can restore the nitroxide-enhanced MRI contrast (Zhelev et al. 2015; Bacic et al. 2016; Maulucci et al. 2016).

We analyzed the level of ROS and total antioxidant (reducing) capacity of kidney on isolated tissue specimens, using conventional tests (Figure 5). A significant increase of ROS and a significant decrease of total antioxidant capacity were found in $\mathrm{CD}$ mice compared to ND mice. A slight but insignificant increase of ROS was detected in CC mice, while the total antioxidant capacity was at the control level. These data indicate a development of oxidative stress in the kidney of mice with hypercholesterolemia and a relatively normal redox-status of renal tissues in mice, treated with cholestyramine.

Another important factor can also influence the dynamics of MRI contrast. This is the penetration of nitroxide into the tissues and the rate of excretion from the organism.

Brasch (1983) has investigated the dynamics of nitroxideenhanced MRI in the kidneys of healthy animals and animals with experimental renal ischemia and hydronephritis. The author used the amphiphilic nitroxide radical, 4-[(3-carboxy1-oxopropyl)amino]-2,2,6,6-tetramethyl-1-piperidinyloxy 

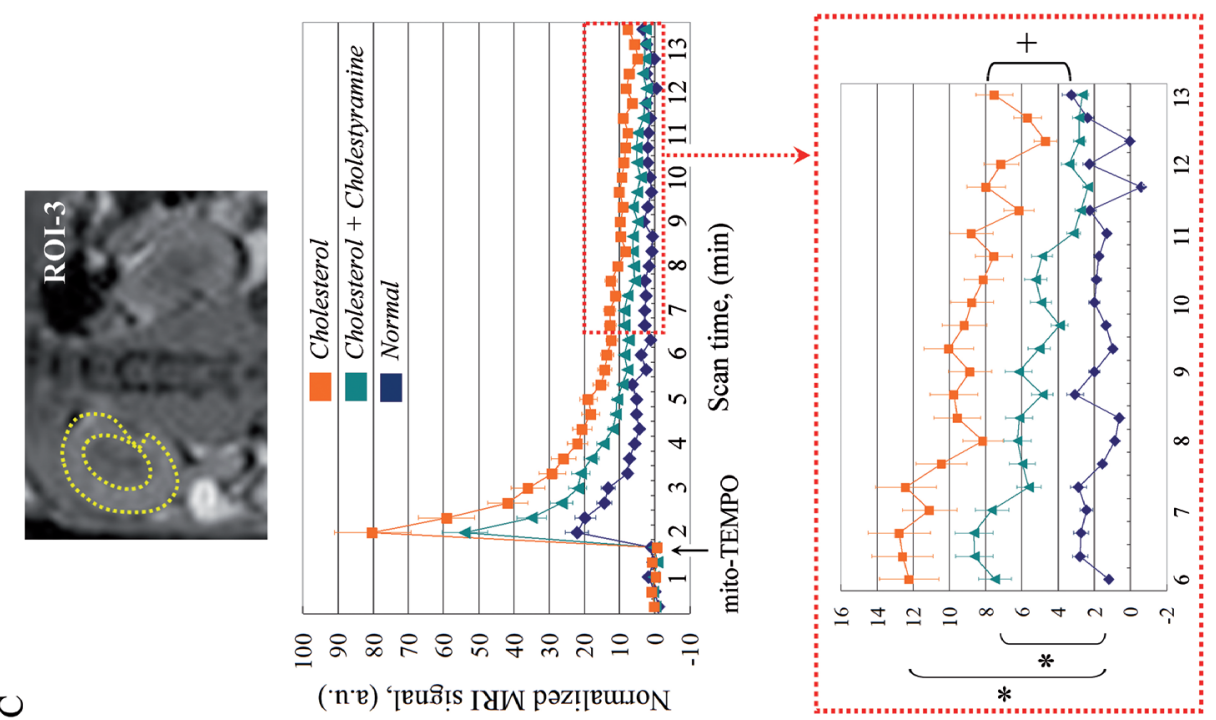

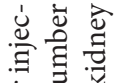

可 表

营 $=\frac{0}{0}$

సै के

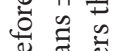

วิ

บ

กิ

承 :

可 $\dot{0}$

疍 11 ن

过

$\exists$.

U

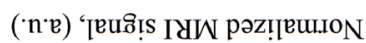

चี

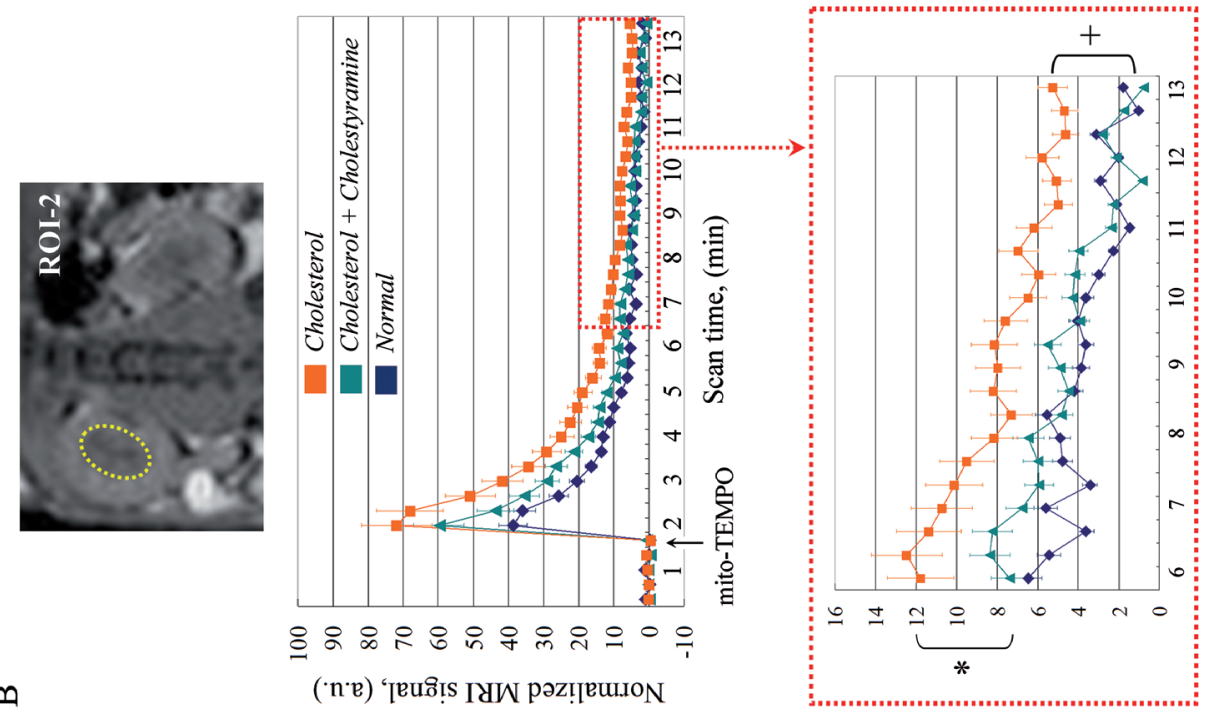

ฮู 苛

ते

象完

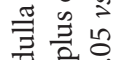

웅

胥芯芯.

월 웡

.

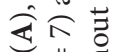

돈

Oن

ध्र

ลे.

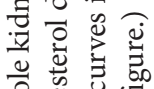

$m$

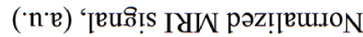

उ

ป ज

ถิก

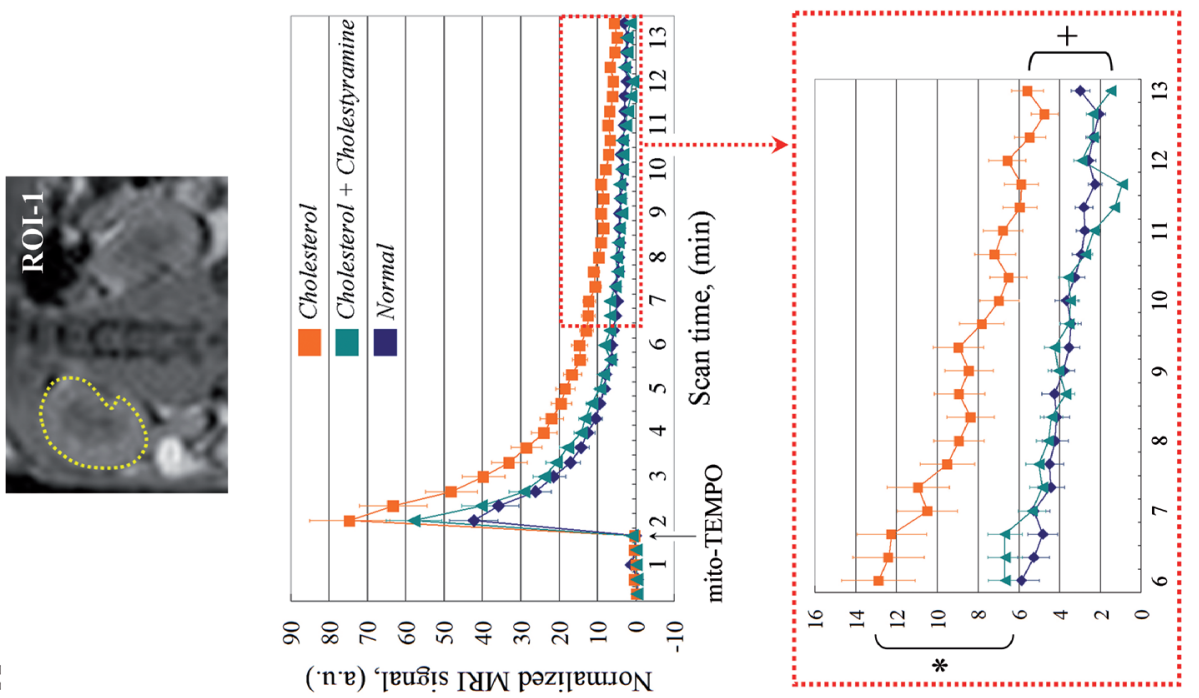

灵文各

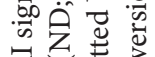

종 웡

공

크 $\Xi$

寄造

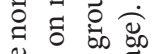

‡.

品

$\Rightarrow 0$ 뭉

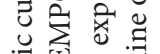

氖氜

讨 웜

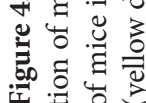


A

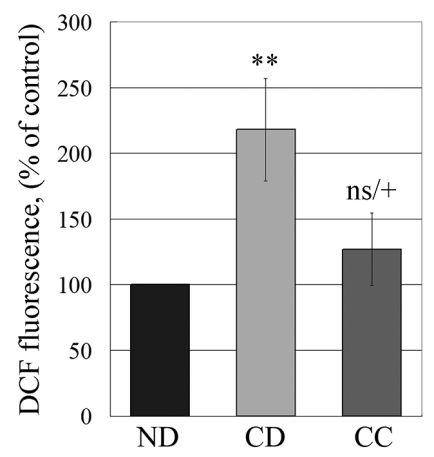

B

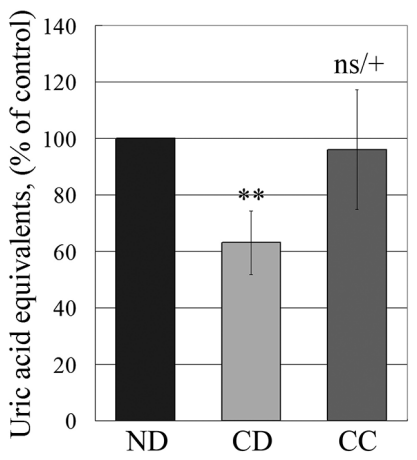

Figure 5. Level of reactive oxygene species (ROS) (A) and total antioxidant (reducing) capacity (B) of kidneys, detected by conventional analytical test on isolated tissue specimens in vitro. The data are means \pm SD from 5 mice in ND group and 7 mice in CD group and CC group. The mice were 20-weeks of age. ns, non-significant, ${ }^{* *} p<0.01$ vs. ND group; $+p<0.05 v s$. CD group. For more abbreviations, see Fig. 2.
(TES), that penetrates into cells and tissues. An increased contrast is found in damaged kidneys compared to kidneys in healthy animals. These observations are explained by disorders of vascular permeability and increased diffusion of the nitroxide into the lesions. No conventional contrast agent, such as gadolinium complex, has been used to demonstrate the penetration and retention of nitroxide in the lesions. The authors do not discuss the redox-status of the lesions and its potential impact on the redox-status of the nitroxide probe, respectively on the dynamics of nitroxide-enhanced MRI signal. It is known that renal ischemia and hydronephritis are accompanied by induction of severe oxidative stress in the kidneys due to mitochondrial dysfunction and production of variety of inflammatory factors and ROS/RNS (Kettler et al. 2003; Ruiz et al. 2005; Malek and Nematbakhsh 2015; Rovcanin et al. 2016; Baligard et al. 2017; Stokman et al. 2017). Numerous studies have also shown decreased perfusion in damaged kidneys (Mathew et al. 2007; Baligard et al. 2017), which implies a difficult penetration of contrast agent in this organ. Therefore, the increased contrast of TES in the damaged kidney after ischemia/reperfusion is most likely a result of oxidative stress and existence of nitroxide mainly in a radical form.

It is considered that the changes in the structure and function of renal cells, caused by hypercholesterolemia, are preceded by changes in the renal vasculature-increased microvascularization in the renal cortex (in the initial phase of hypercholesterolemia) and subsequent calcification (Kettler et al. 2003; Ruiz et al. 2005; Mathew et al. 2007). Our previous study also shows that hypercholesterolemia-induced renal dysfunction is characterized by glomerulosclerosis and degeneration of proximal tubules (Tomizawa et al. 2011a). In the same experimental model, we did not observe any nitroxide-enhanced MRI signal in the kidneys of CD mice, using carbamoyl-PROXYL (CMPx) as a contrast probe (Figure 6A). However, this observation was not a result of a rapid reduction of the nitroxide radical to its diamagnetic form in the renal tissues of CD mice. This was a result of strongly decreased perfusion, which was demonstrated by a gadolinium-enhanced MRI (Figure 6B).

The cell penetration of CMPx in cells is practically "zero" in vivo, because this process competes with the relatively rapid excretion from the mouse (Togashi et al. 2000; Hyodo et al. 2006b). CMPx is recorded by MRI in the bladder of healthy mice at the $2^{\text {nd }}$ minute after tail injection (Togashi et al. 2000; Hyodo et al. 2006b), but not in the bladder of mice with hypercholesterolemia (Tomizawa et al. 2011a). Moreover, we found that the serum albumin decreased significantly in $\mathrm{CD}$ mice, which would accelerate the renal filtration of nitroxide and its excretion from the organism, compared to ND mice. However, the nitroxide-enhanced MRI signal has higher intensity and longer life-time than in ND mice. All these data provide indirect evidence that the higher intensity of MRI signal of mito-TEMPO in the kidneys of CD mice is mainly due to the higher oxidative capacity of renal tissues compared to ND mice.

Cyclic nitroxides are relatively low toxic (much safer than gadolinium complexes) and are not mutagenic (Ankel et al. 1987; Damiani et al. 2000). They are characterized by favorable biomedical effects, such as: anticancer effect, regulation of body weight, protection against ischemia-reperfusion injury, protective effect against cataract, sensitizing cancer cells and tissues to ionizing radiation and protecting normal cells and tissues, etc. (Soule et al. 2007a, 2007b; Zuo et al. 2009; Dikalova et al. 2010; Liu et al. 2018). Moreover, some cyclic nitroxides are already in clinical trials, currently for topical applications (Zarlin et al. 2015). This proves the potential of nitroxides as new contrast substances for redox-imaging in translational studies on humans, by using MRI. However, this can be achieved after many preliminary studies on experimental animals in order to select most appropriate nitroxide probes for redox-imaging, route of their administration and safe doses. In this context, our study shows that the higher sensitivity of cell-penetrating piperidine-type nitroxides to reduction should not be considered as a disadvantage. This provides a new opportunity for MRI/EPRI analysis 
of metabolic pathways, accompanied by minor changes in the reducing capacity of biological objects and induction of oxidative stress.

\section{Conclusions}

The present study shows that mito-TEMPO is appropriate contrast probe for magnetic resonance imaging of
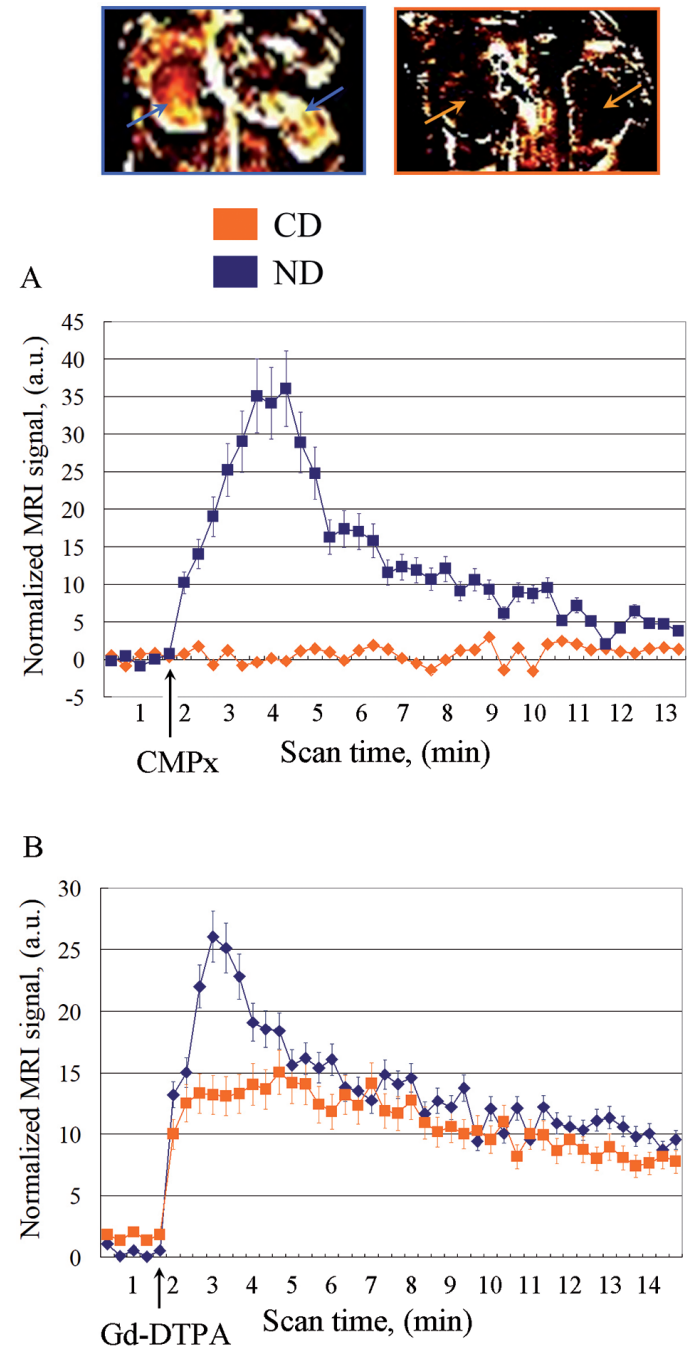

Figure 6. Kinetic curves of the normalized MRI signal before and after injection of carbamoyl-PROXYL (CMPx) (A) or Gd-DTPA (B) in mice on a normal diet (ND) or cholesterol diet (CD). In the images: Blue arrows indicate the extracted nitroxide-enhanced MRI signal, normalized to the baseline, detected in the kidneys of ND mice. Orange arrows indicate absence of nitroxide enhancement in the kidneys of CD mice. The images were obtained 2 minutes after injection of CMPx in the respective animal. The mice were 15-weeks of age (according to Tomizawa et al. 2011b). (See online version for color figure.) hypercholesterolemia-induced kidney dysfunction based on impaired redox-capacity of renal tissues. The probe is also suitable for assessing the effect of anti-lipidemic drugs. The experimental data suggest that hypercholesterolemia induces oxidative stress in kidney and this process could be visualized using MRI and cell-penetrating nitroxide radicals as redoxsensitive contrast substances (in particular, mito-TEMPO). The comparative analysis with our previous study (Tomizawa et al. 2011a) shows that hydrophilic nitroxide radicals (such as $\mathrm{CMPx}$ ), that poorly penetrate or non-penetrate into the cells, are not suitable for "redox-imaging" of kidney dysfunction, accompanied by oxidative stress and severely decreased filtration due to glomerulosclerosis. The early diagnosis of kidney dysfunction based on tissue redox-status could have a significant clinical impact.

Acknowledgements. We would like to thank Mr. Yoshikazu Ozawa (from the National Institute for Radiological Sciences, QST-NIRS, Chiba, Japan) for his assistance during MRI experiments. This study was partially supported by the Grant-in-aid "Kakenhi-C" from the Japanese Society for the Promotion of Science (JSPS) (granted to R.B.) and by the Project for Cancer Research and Therapeutic Evolution (P-CREATE) (Project No.16 $\mathrm{cm} 0106202 \mathrm{~h} 0001$ ) from the Japanese Agency for Medical Research and Development (AMED).

Conflict of interest. All authors declare that there is no conflict of interests.

\section{References}

Ankel E, Lai CS, Hopwood LE, Zivkovic Z (1987): Cytotoxicity of commonly used nitroxide radical spin probes. Life Sci. 40, 495-498 https://doi.org/10.1016/0024-3205(87)90116-0

Bacic G, Pavicevic A, Peyrot F (2016): In vivo evaluation of different alterations of redox status by studying pharmacokinetics of nitroxides using magnetic resonance techniques. Redox Biol. 8, 226-242 https://doi.org/10.1016/j.redox.2015.10.007

Bagshaw SM, Culleton BF (2006): Contrast-induced nephropathy: epidemiology and prevention. Minerva Cardioangiol. 54, 109-129

Bakalova R, Zhelev Z, Aoki I, Saga T (2013): Tissue redox activity as a hallmark of carcinogenesis: from early to terminal stage of cancer. Clin. Cancer Res. 19, 2503-2517 https://doi.org/10.1158/1078-0432.CCR-12-3726

Baligard C, Qin H, True-Yasaki A, Gordon JW, von Morze C, Santos JD, Wilson DM. Raffai R, Cowley PM, Baker AJ, et al. (2017): Hyperpolarized 13C magnetic resonance evaluation of renal ischemia reperfusion injury in a murine model. NMR Biomed. 30, e3765 https://doi.org/10.1002/nbm.3765

Bashir MR, Jaffe TA, Brennan TV, Patel UD, Ellis MJ (2013): Renal transplant imaging using magnetic resonance angiography 
with a non-nephrotoxoc contrast agent. Transplantation 96, 91-96 https://doi.org/10.1097/TP.0b013e318295464c

Batinic-Haberle I, Reboucas JS, Spasijevic I (2010): Superoxide dismutase mimetics: chemistry, pharmacology, and therapeutic potential. Antioxid. Redox Signal. 13, 877-918 https://doi.org/10.1089/ars.2009.2876

Bentley MD, Rodriguez-Porcel M, Lerman A, Sarafov MH, Romero JC, Pelaez LI, Grande JP, Ritman EI, Lerman LO (2002): Enhanced renal cortical vascularization in experimental hypercholesterolemia. Kidney Int. 61, 1056-1063 https://doi.org/10.1046/j.1523-1755.2002.00211.x

Betjes MG (2013): Immune cell dysfunction and inflammation in end-stage renal disease. Nat. Rev. Nephrol. 9, 255-265 https://doi.org/10.1038/nrneph.2013.44

Bobko AA, Kirilyuk IA, Grigor'ev IA, Zweier JL, Khramtsov VV (2007): Reversible reduction of nitroxides to hydroxylamines: the roles for ascorbate and glutathione. Free Radic. Biol. Med. 42, 404-412 https://doi.org/10.1016/j.freeradbiomed.2006.11.007

Brasch RC (1983): Work in progress: methods of contrast enhancement for NMR imaging and potential applications. A subject review. Radiology 147, 781-788 https://doi.org/10.1148/radiology.147.3.6342034

Cachofeiro V, Goicochea M, de Vinuesa SG, Oubina P, Lahera V, Luno J (2008): Oxidative stress and inflammation, a link between chronic kidney disease and cardiovascular disease. Kidney Int. Suppl. 111, S4-S9 https://doi.org/10.1038/ki.2008.516

Chen K, Glockner JF, Morse PD, Swartz HM (1989): Effects of oxygen on the metabolism of nitroxide spin labels in cells. Biochemistry 28, 2496-2501 https://doi.org/10.1021/bi00432a022

Cheng ZZ, Patari A, Aalto-Setala K, Novikov D, Schlondorff D, Holhofer H (2003): Hypercholesterolemia is a prerequisite for puromycin inducible damage in mouse kidney. Kidney Int. 63, 107-112 https://doi.org/10.1046/j.1523-1755.2003.00726.x

Damiani E, Greci L, Hrelia P (2000): Cyto- and genotoxic effects of novel aromatic nitroxide radicals in vitro. Free Radic. Biol. Med. 28, 330-336 https://doi.org/10.1016/S0891-5849(99)00245-2

Deepa PR, Varalakshmi P (2003): Salubrious effect of low molecular weight heparin on atherogenic diet-induced cardiac, hepatic and renal lipid peroxidation and collapse of antioxidant defences. Mol. Cell. Biochem. 254, 111-116

Dikalov SI, Harrison DG (2014): Methods for detection of mitochondrial and cellular reactive oxygen species. Antioxid. Redox Signal. 20, 372-372 https://doi.org/10.1089/ars.2012.4886

Dikalova AE, Bikineyeva AT, Budzyn K, Nazarewicz RR, McCann L, Lewis W, Harrison DG, Dikalov SI (2010): Therapeutic targeting of mitochondrial superoxide in hypertension. Circ. Res. 107, 106-116 https://doi.org/10.1161/CIRCRESAHA.109.214601

Domrongkitchaiporn S, Sritara P, Kitiyakara C, Stitchantrakul W, Krittaphol V, Lolekha P, Cheepudomwit S, Yipintsoi T (2005): Risk factors for development of decreased kidney function in a Southeast Asian population: A 12-year cohort study. J. Am. Soc. Nephrol. 16, 791-799 https://doi.org/10.1681/ASN.2004030208

Dong Y, Wang WP, Cao J, Fan P, Lin X (2014): Early assessment of chronic kidney dysfunction using contrast-enhanced ultrasound: a pilot study. Br. J. Radiol. 87, 20140350 https://doi.org/10.1259/bjr.20140350

Eddy AA (1998): Intestinal fibrosis in hypercholesterolemic rats: role of oxidation, matrix synthesis, and proteolytic cascades. Kidney Int. 53, 1182-1189 https://doi.org/10.1046/j.1523-1755.1998.00889.x

El-Baz A, Fahmi R, Yuksel S, Farag AA, Miller W, El-Ghar MA, Eldiasty T (2006): A new CAD system for the evaluation of kidney disease using DCE-MRI. Med. Image Comput. Comput. Assist. Invest. 9, 446-453 https://doi.org/10.1007/11866763_55

Fang Q, Zou C, Zhong P, Lin F, Li W, Wang L, Zhang Y, Zheng C, Wang Y, Li X, Liang G (2016): EGFR mediates hyperlipidemiainduced renal injury via regulating inflammation and oxidative stress: the detrimental role and mechanism of EGFR activation. Oncotarget 7, 24361-24373 https://doi.org/10.18632/oncotarget.8222

Fuchs J, Groth N, Herrling T, Zimmer G (1997): Electron paramagnetic resonance studies on nitroxide radical 2,2,5,5-tetramethyl-4-piperidin-1-oxyl (TEMPO) redox reactions in human skin. Free Radic. Biol. Med. 22, 967-976 https://doi.org/10.1016/S0891-5849(96)00433-9

Gamboa JL, Billing FT, Bojanowski MT, Gilliam LA, Yu C, Roshanravan B, Jackson Roberts L, Himmelfarb J, Brown NJ (2016): Mitochondrial dysfunction and oxidative stress in patients with chronic kidney disease. Physiol. Rep. 4, e12780 https://doi.org/10.14814/phy2.12780

Georgieva E, Ivanova D, Zhelev Z, Bakalova R, Gulubova M, Aoki I (2017): Mitochondrial dysfunction and redox imbalance as a diagnostic marker of „free radical diseases“. Anticancer Res. 37, 5373-5381 https://doi.org/10.21873/anticanres.11963

Hermankova E, Zak A, Polakova L, Hobzova R, Hromadka R, Sirc $J$ (2018): Polymeric bile acid sequestrants: Review of design, in vitro binding activities, and hypocholesterolemic effects. Eur. J. Med. Chem. 144, 300-317 https://doi.org/10.1016/j.ejmech.2017.12.015

Hirayama A, Nagase S, Ueda A, Oteki T, Takada K, Obara M, Inoue M, Yoh K, Hirayama K, Koyama A (2005): In vivo imaging of oxidative stress in ischemia-reperfusion renal injury using electron paramagnetic resonance. Am. J. Physiol. Renal. Physiol. 288, F597-F603 https://doi.org/10.1152/ajprenal.00020.2004

Hirayama A, Ueda A, Oteki T, Nagase S, Aoyagi K, Koyama A (2008): In vivo imaging of renal redox status during azelnidipine treatment. Hypertens. Res. 31, 1643-1650 https://doi.org/10.1291/hypres.31.1643

Hyodo F, Yasukawa K, Yamada K-I, Utsumi H (2006a): Spatially resolved time-course studies of free radical reactions with an EPRI/MRI fusion technique. Magn. Reson. Med. 56, 938-943 https://doi.org/10.1002/mrm.21019

Hyodo F, Matsumoto K, Matsumoto A, Mitchell JB, Krishna MC (2006b): Probing the intracellular redox status of tumors with 
MRI and redox-sensitive contrast agents. Cancer Res. 66, 9921-9928

https://doi.org/10.1158/0008-5472.CAN-06-0879

Ilori TO, Sun RY, Kong SY, Gutierrez OM, Ojo AO, Judd SE, Narayan KM, Goodman M, Plantinga L, McClellan W (2015): Oxidative balance score and chronic kidney disease. Am. J. Nephrol. 42, 320-327 https://doi.org/10.1159/000441623

Kalyanaraman B, Darley-Usmar V, Davies KJ, Dennery PA, Forman HJ, Grisham MB, Mann GE, Moore K, Roberts LJ, Ischiropoulos $\mathrm{H}$ (2012): Measuring reactive oxygen and nitrogen species with fluorescent probes: challenges and limitations. Free Radic. Biol. Med. 52, 1-6 https://doi.org/10.1016/j.freeradbiomed.2011.09.030

Kamanna VS, Roh DD, Kirschenbaum MA (1998): Hyperlipidemia and kidney disease: concepts derived from histopathology and cell biology of the glomerulus. Histol. Histopathol. 13, 169-179

Ketteler M, Wanner C, Metzger T, Bongartz P, Westenfeld R, Gladziwa U, Schurgers LJ, Vermeer C, Jahnen-Dechent W, Floege J (2003): Deficiencies of calcium-regulatory proteins in dialysis patients: a novel concept of cardiovascular calcification in uremia. Kidney Int. Suppl. 84, S84-S87 https://doi.org/10.1046/j.1523-1755.63.s84.21.x

Kon V, Linton MRF, Fazio S (2011): Atherosclerosis in chronic kidney disease: the role of macrophages. Nat. Rev. Nephrol. 7, 45-54 https://doi.org/10.1038/nrneph.2010.157

Kondo Y, Ikeda K, Tokuda N, Nishitani C, Ohto U, AkashiTakamura S, Ito Y, Uchikawa M, Kuroki Y, Taguchi R, et al. (2013): TLR4-MD-2 complex is negatively regulated by an endogenous ligand, globotetraosylceramide. Proc. Natl. Acad. Sci. USA 110, 4714-4719 https://doi.org/10.1073/pnas.1218508110

Kuppusamy P, Afeworki M, Shankar RA, Coffin D, Krishna MC, Hahn SM, Mitchell JB, Zweier JL (1998): In vivo electron paramagnetic resonance imaging of tumor heterogeneity and oxygenation in a murine model. Cancer Res. 58, 1562-1568

Kuppusamy P, Li H, Ilangovan G, Cardounel AJ, Zweier JL, Yamada K, Krishna MC, Mitchell JB (2002): Noninvasive imaging of tumor redox status and its modification by tissue glutathione level. Cancer Res. 62, 307-312

Likhtenshtein GI, Yamauchi J, Nakatsuji S, Smirnov AI, Tamura R (2008): Nitroxides: Applications in Chemistry, Biomedicine, and Material Science. Wiley-VCH, Weinheim, Germany https://doi.org/10.1002/9783527621743

Liu Y, Wang Y, Ding W, Wang Y (2018): Mito-TEMPO alleviates renal fibrosis by reducing inflammation, mitochondrial dysfunction, and endoplasmic reticulum stress. Oxid. Med. Cell. Longev. 2018, 5828120 https://doi.org/10.1155/2018/5828120

Malek M, Nematbakhsh M (2015): Renal ischemia/reperfusion injury: from pathology to treatment. J. Renal Inj. Prev. 4, $20-27$

Mathew S, Lund RJ, Strebeck F, Tustison KS, Geurs T, Hruska KA (2007): Reversal of the adynamic bone disorder and decreased vascular calcification in chronic kidney disease by sevelamer carbonate therapy. J. Am. Soc. Nephrol. 8, 122-123
https://doi.org/10.1681/ASN.2006050490

Matsumoto S, Koshiishi I, Inoguchi T, Nawata H, Utsumi H (2003): Confirmation of superoxide generation via xanthine oxidase in streptozotocin-induced diabetic mice. Free Radic. Res. 37, 767-772 https://doi.org/10.1080/1071576031000107344

Matsumoto K, Hyodo F, Matsumoto A, Koretsky AP, Sowers AL, Mitchell JB, Krishna MC (2006): High-resolution mapping of tumor redox status by MRI using nitroxides as redox-sensitive contrast agents. Clin. Cancer Res. 12, 2455-2462 https://doi.org/10.1158/1078-0432.CCR-05-2747

Maulucci G, Bacic G, Bridal L, Schmidt H, Tavitian B, Viel T, Utsumi H, Yalcin AS, De Spirito M (2016): Imaging of ROSinduced modifications in living cells. Antioxid. Redox Signal. 24, 939-957 https://doi.org/10.1089/ars.2015.6415

Mehlhorn RJ (1991): Ascorbate- and dehydroascorbic acid-mediated reduction of free radicals in the human erythrocytes. J. Biol. Chem. 266, 2724-2731

Mikuni T, He G, Petryakov S, Fallouh MM, Deng Y, Ishihara R, Kuppusamy P, Tatsuta M, Zweier JL (2004): In vivo detection of gastric cancer in rats by electron paramagnetic resonance imaging. Cancer Res. 64, 6495-6502 https://doi.org/10.1158/0008-5472.CAN-04-0319

Milman Z, Axelrod JH, Heyman SN, Nachmansson N, Abramovich R (2014): Assessment with unenhanced MRI techniques of renal morphology and hemodynamic changes during acute kidney injury and chronic kidney disease in mice. Am. J. Nephrol. 39, 268-278 https://doi.org/10.1159/000360093

Montilla P, Espejo I, Munoz MC, Bujalance I, Munoz-Castaneda JR, Tunes I (2006): Protective effect of red wine on oxidative stress and antioxidant enzyme activities in the brain and kidney induced by feeding high cholesterol in rats. Clin. Nutr. 25, 146-153 https://doi.org/10.1016/j.clnu.2005.10.004

Nagata M, Ninomiya T, Doi Y, Yonemoto K, Kubo M, Hata J, Tsuruya K, Iiida M, Iida M, Kiyohara Y (2010): Trends in the prevalence of chronic kidney disease and its risk factors in a general Japanese population: The Hisayama Study. Nephrol. Dial. Transplant. 25, 2557-2564 https://doi.org/10.1093/ndt/gfq062

Okamura DM, Pennathur S, Pasichnuk K, Lopez-Guisa JM, Collins S, Febbraio M, Heinecke J, Eddy AA (2009): CD36 regulates oxidative stress and inflammation in hypercholesterolemic CKD. J. Am. Soc. Nephrol. 20, 495-505

https://doi.org/10.1681/ASN.2008010009

Prowle JR, Molan MP, Hornsey E, Bellomo R (2010): Cine phasecontrast MRI for the measurement of renal blood flow. Contrib. Nephrol. 165, 329-336 https://doi.org/10.1159/000313774

Qiao M, Zhao Q, Lee CF, Tannlock LR, Smart EJ, LeBaron RG, Phelix CF, Rangel Y, Asmis R (2009): Thiol oxidative stress induced by metabolic disorders amplifies macrophage chemotactic response and accelerates atherogenic and kidney injury in LDL receptor-deficient mice. Arterioscler. Thromb. Vasc. Biol. 29, 1779-1786 https://doi.org/10.1161/ATVBAHA.109.191759 
Rodriguez-Porcel M, Krier JD, Lerman A, Sheedy PF, Romero JC, Napoli C, Lerman LO (2001): Conbination of hypercholesterolemia and hypertension augments renal function abnormalities. Hypertension 37, 774-780 https://doi.org/10.1161/01.HYP.37.2.774

Rovcanin B, Medic B, Kocic G, Cebovic T, Ristic M, Prostran M (2016): Molecular dissection of renal ischemia-reperfusion: Oxidative stress and cellular events. Curr. Med. Chem. 23, 1965-1980 https://doi.org/10.2174/0929867323666160112122858

Ruiz MC, Medina A, Moreno JM, Gomez I, Ruiz N, Bueno P, Asensio C, Osuna A (2005): Relationship between oxidative stress parameters and atherosclerotic signs in the carotid artery of stable renal transplant patients. Transplant. Proc. 37, 3796-3798

https://doi.org/10.1016/j.transproceed.2005.10.057

Samuni A, Goldstein S, Russo A, Mitchell JB, Krishna MC, Neta $P$ (2002): Kinetics and mechanism of hydroxyl radical and $\mathrm{OH}$-adduct radical reactions with nitroxides and with their hydroxylamines. J. Am. Chem. Soc. 124, 8719-8724 https://doi.org/10.1021/ja017587h

Samuni Y, Gamson J, Samuni A, Yamada K, Russo A, Krishna MC, Mitchell JB (2004): Factors influencing nitroxide reduction and cytotoxicity in vitro. Antioxid. Redox Signal. 6, 587-595 https://doi.org/10.1089/152308604773934341

Sano T, Umeda F, Hashimoto T, Nawata H, Utsumi H (1998): Oxidative stress measurement by in vivo electron spin resonance spectroscopy in rats with streptozotocin-induced diabetes. Diabetologia 41, 1355-1360 https://doi.org/10.1007/s001250051076

Sonta T, Inoguchi T, Tsubouchi H, Sekiguchi N, Kobayashi K, Matsumoto S, Utsumi H, Nawata H (2004): Evidence for contribution of vascular NAD(P)H oxidase to increased oxidative stress in animal models of diabetes and obesity. Free Radic. Biol. Med. 37, 115-123 https://doi.org/10.1016/j.freeradbiomed.2004.04.001

Sonta T, Inoguchi T, Matsumoto S, Yasukawa K, Inuo M, Tsubouchi H, Sonoda N, Kobayashi K, Utsumi H, Nawata H (2005): In vivo imaging of oxidative stress in the kidney of diabetic mice and its normalization by angiotensin II type 1 receptor blocker. Biochem. Biophys. Res. Commun. 330, 415-422 https://doi.org/10.1016/j.bbrc.2005.02.174

Soule BP, Hyodo F, Matsumoto K, Simone NL, Cook JA, Krishna MC, Mitchell JB (2007a): The chemistry and biology of nitroxide compounds. Free Radic. Biol. Med. 42, 1632-1650 https://doi.org/10.1016/j.freeradbiomed.2007.02.030

Soule BP, Hyodo F, Matsumoto K, Simone NL, Cook JA, Krishna MC, Mitchell JB (2007b): Therapeutic and clinical applications of nitroxide compounds. Antioxid. Redox Signal. 9, $1731-1743$ https://doi.org/10.1089/ars.2007.1722

Stokman G, Kors L, Bakker PJ, Rampanelli E, Claessen N, Teske GJD, Butter L, van Andel H, van den Bergh Weerman MA, Larsen PWB, et al. (2017): NLRX1 dampens oxidative stress and apoptosis in tissue injury via control of mitochondrial activity. J. Exp. Med. 214, 2405-2420 https://doi.org/10.1084/jem.20161031
Suzuki-Nishimura T, Swartz HM (1994): Reduction of lipid-soluble nitroxides in $\mathrm{CHO}$ cells and macrophage tumor cells. Free Radic. Biol. Med. 17, 473-479

https://doi.org/10.1016/0891-5849(94)90174-0

Suzuki-Nishimura T, Swartz HM (1998): Characterization of redox activity in resting and activated mast cells by reduction and reoxidation of lipophilic nitroxides. Gen. Pharmacol. 31, 617-623 https://doi.org/10.1016/S0306-3623(98)00066-4

Swartz HM, Sentjurc M, Morse PD (1986): Cellular metabolism of water-soluble nitroxides: effect on rate of reduction of cell/ nitroxide ratio, oxygen concentrations and permeability of nitroxides. Biochim. Biophys. Acta 888, 82-90 https://doi.org/10.1016/0167-4889(86)90073-X

Togashi H, Matsuo T, Shinzawa H, Takeda Y, Shao L, Oikawa K, Kamada H, Takahashi T (2000): Ex vivo measurement of tissue distribution of a nitroxide radical after intravenous injection and its in vivo imaging using a rapid scan ESR-CT system. Magn. Reson. Imaging 18, 151-156 https://doi.org/10.1016/S0730-725X(99)00122-8

Tomizawa A, Ishii I, Zhelev Z, Aoki I, Shibata S, Kitada M, Bakalova R (2011a): Carbamoyl-PROXYL-enhanced MRI detects very small disruptions in brain vascular permeability induced by dietary cholesterol. Biochim. Biophys. Acta 1810, $1309-1316$ https://doi.org/10.1016/j.bbagen.2011.06.011

Tomizawa A, Hadjidekov G, Ishii I, Bakalova R, Zhelev Z, Aoki I, Saga T, Kitada M (2011b): Nitroxide derivatives for imaging of hypercholesterolemia-induced kidney dysfunction and assessing the effectiveness of antilipidemic drugs. Mol. Pharm. 8, 1962-1969 https://doi.org/10.1021/mp200087v

Tsubouchi H, Inoguchi T, Sonta T, Sato N, Sekiguchi N, Kobayashi K, Sumimoto H, Utsumi H, Nawata H (2005): Statin attenuates high glucose-induced and diabetes-induced oxidative stress in vitro and in vivo evaluated by electron spin resonance measurement. Free Radic. Biol. Med. 39, 444-452 https://doi.org/10.1016/j.freeradbiomed.2005.03.031

Tucker PS, Dalbo VJ, Han T, Kingsley MI (2013): Clinical and research markers of oxidative stress in chronic kidney disease. Biomarkers 18, 103-115

https://doi.org/10.3109/1354750X.2012.749302

Vogl T, Tenbrock K, Ludwig S, Leukert N, Ehrhardt C, van Zoelen MA, Nacken W, Foell D, van der Poll T, Sorg C, Roth J (2007): Mrp8 and Mrp14 are endogenous activators of Toll-like receptor 4 , promoting lethal, endotoxin-induced shock. Nat. Med. 13, 1042-1049 https://doi.org/10.1038/nm1638

Vostalova J, Galandakova A, Svobodova AR, Orolinova E, Kajabova M, Schneiderka P, Zapletalova J, Strebl P, Zadrazil J (2012): Time-course evaluation of oxidative stress-related biomarkers after renal transplantation. Ren. Fail. 34, 413-419 https://doi.org/10.3109/0886022X.2011.649658

Wan C, Su H, Zhang C (2016): Role of NADPH oxidase in metabolic disease-related renal injury: An update. Oxid. Med. Cell. Longev. 2016, 7813072

https://doi.org/10.1155/2016/7813072

Yamada K-I, Kuppusamy P, English S, Yoo J, Irie A, Subramanian S, Mitchell JB, Krishna MC (2002): Feasibility and assessment of 
non-invasive in vivo redox status using electron paramagnetic resonance imaging. Acta Radiol. 43, 433-440 https://doi.org/10.1034/j.1600-0455.2002.430418.x

Zarling JA, Brunt VE, Vallegra AK, Li W, Tao A, Zarling DA, Minson CT (2015): Nitroxide pharmaceutical development for age-related degeneration and disease. Front. Gen. 6, art. 325 https://doi.org/10.3389/fgene.2015.00325

Zhang R, Goldstein S, Samuni A (1999): Kinetics of superoxideinduced exchange among nitroxide antioxidants and their oxidized and reduced forms. Free Radic. Biol. Med. 26, $1245-1252$ https://doi.org/10.1016/S0891-5849(98)00328-1

Zhelev Z, Bakalova R, Aoki I, Matsumoto K, Gadjeva V, Anzai K, Kanno I (2009a): Nitroxide radicals for labeling of conventional therapeutics and noninvasive magnetic resonance imaging of their permeabilitt for blood-brain barrier: relationship between structure, blood clearance, and MRI signal dynamics in the brain. Mol. Pharm. 6, 504-512 https://doi.org/10.1021/mp800175k

Zhelev Z, Matsumoto K, Gadjeva V, Bakalova R, Aoki I, Zheleva A, Anzai K (2009b): Tissue redox activity as a hallmark of carcinogenesis: from early to terminal stages of cancer. Gen. Physiol. Biophys. 28, 356-362
Zhelev Z, Gadjeva V, Aoki I, Bakalova R, Saga T (2012): Cellpenetrating nitroxides as molecular sensors for imaging of cancer in vivo, based on tissue redox activity. Mol. BioSystems 8, 2733-2740 https://doi.org/10.1039/c2mb25128k

Zhelev Z, Aoki I, Gadjeva V, Nikolova B, Bakalova R, Saga T (2013): Tissue redox activity as a sensing platform for imaging of cancer based on nitroxide redox cycle. Eur. J. Cancer 49, 1467-1478 https://doi.org/10.1016/j.ejca.2012.10.026

Zhelev Z, Bakalova R, Aoki I, Lazarova D, Saga T (2015): Magnetic resonance imaging of mitochondrial dysfunction and metabolic activity accompanied by overproduction of superoxide. ACS Chem. Neurosci. 6, 1922-1929 https://doi.org/10.1021/acschemneuro.5b00220

Zuo L, Chen YR, Reyes LA, Lee HL, Chen CL, Villamena FA, Zweier JL (2009): The radical trap 5,5-dimethyl-1-pyrroline $\mathrm{N}$-oxide exerts dose-dependent protection against myocardial ischemia-reperfusion injury through preservation of mitochondrial electron transport. J. Pharmacol. Exp. Ther. 329, 515-523

https://doi.org/10.1124/jpet.108.143479

Received: September 28, 2018

Final version accepted: January 3, 2019 


\title{
Nitroxide-enhanced magnetic resonance imaging of kidney
} dysfunction in vivo based on redox-imbalance and oxidative stress

\author{
Dessislava Lazarova ${ }^{1}$, Sayaka Shibata ${ }^{2}$, Itsuko Ishii ${ }^{3}$, Genoveva Zlateva ${ }^{3}$, Zhivko Zhelev ${ }^{4,5}$, \\ Ichio Aoki ${ }^{2,6}$, Tatsuya Higashi ${ }^{6}$ and Rumiana Bakalova ${ }^{1,2,6}$ \\ ${ }^{1}$ Medical Faculty, Sofia University "St. Kliment Ohridski”, Sofia, Bulgaria \\ ${ }^{2}$ Quantum-state Controlled MRI Group, Institute of Quantum Life Science, National Institutes for Quantum and Radiological \\ Science and Technology (QST), Chiba, Japan \\ ${ }^{3}$ Graduate School of Pharmaceutical Sciences, Japan Chiba University Hospital, Chiba University, Chiba, Japan \\ ${ }^{4}$ Medical Faculty, Trakia University, Stara Zagora, Bulgaria \\ ${ }^{5}$ Institute of Biophysics and Biomedical Engineering, Bulgarian Academy of Sciences, Sofia, Bulgaria \\ ${ }^{6}$ Department of Molecular Imaging and Theranostics, National Institute of Radiological Sciences (NIRS), Chiba, Japan
}

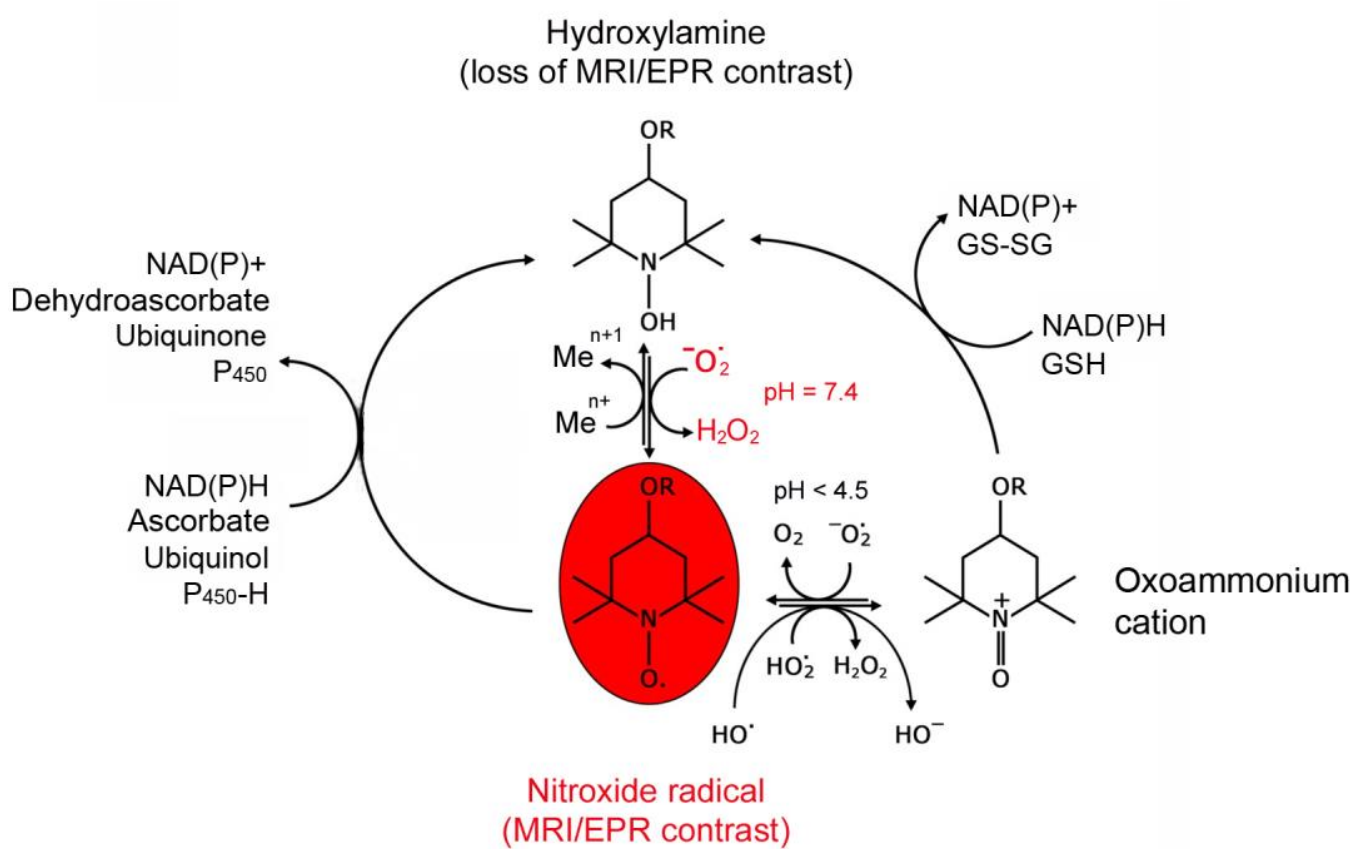

Figure 1S. Redox-cycle of nitroxide and dynamics of its MRI/EPR contrast in living cells and tissues (original scheme; reprinted from Zhelev et al. (2013)).

Correspondence to: Rumiana Bakalova, Group of Quantum-state Controlled MRI, National Institute of Radiological Sciences (QST-NIRS), 4-9-1 Anagawa, Inage-ku, Chiba 263-8555, Japan E-mail: bakalova.rumiana@qst.go.jp. 